\title{
Riding the Waves of Technology: A Study into How SMEs Select Computerized Accounting Software (CAS) supplier in Developing Countries
}

\author{
Maurice Aduamoah \\ Schools of Management, Wuhan University of Technology, \\ Wuhan P.R. China, 430070 \\ Department of Accountancy \& Accounting Information Systems, \\ Kumasi Technical University, Kumasi, Ghana. \\ Song Yinghua \\ Schools of Management, Wuhan University of Technology, \\ Wuhan P.R. China, 430070 \\ Sampson Anomah \\ Department of Accountancy \& Accounting Information Systems, \\ Kumasi Technical University, Kumasi, Ghana.
}

\begin{abstract}
Many SMEs are foreseeing the immense benefits of implementing CAS to facilitate the processing of their financial reporting. This Phenomenon has led to the spread of many CAS products in the software market, making it difficult to select the best among them for implementation. The sub-optimality of CAS is as a result of functionalities such as Scalability ;Capacity; Ease of Data Input ; Security; Speed of Installation ; CAS Consultant/Vendor ; Reporting Capabilities ; Error Handling ; Audit Trail ;Data Validation which are neglected as part of the selection process. CAS is either classified as off-the-shelf package (customised) or bespoke (custom designed).However, this paper concentrates on how SMEs managers select their off-the-shelf CAS (customised) packages in the mist of proliferations of many accounting software in the market. It examined the depth of information which served as guides to SME managers/owners in selecting their currently implemented CAS system. The methodology adopted for the study was the development of a structured questionnaire related to the functionality criteria's above mailed to sample SMEs in the Kumasi Metropolis of Ghana to understand how SMEs choose their CAS packages. The results showed that SMEs desire CAS that are easy to use and vendor support.
\end{abstract}

Keywords: Small and Medium Enterprises, Computerised Accounting Software, Accountants, IT Vendor, Customized/Bespoke

\section{INTRODUCTION}

Deciding on the appropriate CAS package for an SME business has become a challenging topical issue among company managers and stakeholders currently. This is because the risks of selecting the wrong CAS package have led to, financial losses, bankruptcies, closures and disappointments on the part of SMEs and their accounting personnel. Ahmad, (2005) asserts that businesses have evolved from using manual method of keeping financial records to the use of CAS systems. Accounting software packages are now the common applications used in recording and processing accounting data and information in many business organisations such as SMEs. CAS packages have alleviated the stress accountants/bookkeepers go through during manual recording, processing and presentation of financial reports to government 
revenue collection agencies like the Ghana Revenue Authority and SME management. The adoption and implementation of CAS packages have smoothened the recording of financial data and information more easily, quickly and accurately with less overhead expenses argued Ahmad. (2005). Moreover, CAS packages have improved and enhance performance of most accounting functions of SME businesses by generating high quality management information (Collins, (1999); Fisher et al, (2001); (Abu-Musa et al, (2004). However, certain critical success factors in CAS selection process such as Scalability ;Capacity; Ease of Data Input ; Security; Speed of Installation ; CAS Consultant/Vendor ; Reporting Capabilities ; Error Handling ; Audit Trail ;Data Validation and Audit Trail have been overlooked leading to SMEs selecting suboptimal CAS packages which does not meet business objectives and strategies. Alsaaty (2012) is of the view that the information age has necessitated the urgent need for every business organisation to implement automation technologies such as CAS packages. Mpofu et al (2011) posit that SME business owners/managers who fail to adopt Accounting Information Systems (AIS) technologies such as Computerised Accounting Software (CAS) into their regular business operations risk being disadvantaged competitively in terms of meeting deadlines and taking business opportunities. The current happenings in the software market in less developed economies calls for ways to guide SME managers desiring to implement CAS package select best fits to complement what the information age requires now.

For SME businesses, the acquisition of accounting information systems hardware and CAS package are huge capital expenditure. As such, failure to utilise it or unproductive use of that system as a result of incompatibilities are deemed as a costly waste of the SME's budget, time and resources - a potential reversal to the manual method of processing financial data and information with added negative consequences. Unsuccessful implementation and usage of CAS system resulting from sub-optimal selection can also lead to frustration and disappointments among SME owners and employees. It is imperative for SME manager desiring to implement a CAS package be informed of the potential risks exposures and benefits involved selecting both compatible and inharmonious accounting system. SMEs do not have the budget to have a management information department or an IT consultant to lead in the purchase of the CAS system tailored specifically to their needs which are either off-the-shelf or bespoke. As a result, most SME managers have resorted to purchasing off-the-shelf software packages. However, with this method, there is an inherent risk of choosing the wrong CAS package as a result of insufficient and reliable information of the basic functionalities of the accounting package. Usually it is expected that an independent chartered accounting firm would assist in this direction with their own accounting software packages to process accounting data, but most of them do not have the CAS selection and implementation skills in less developed countries such as Ghana. This is due to the fact that as CAS has evolved in advanced countries, it is now evolving in developing countries where most the accounting firms are now learning the packages.

Some SME owners also complained that they do not understand how CAS works because of little or no training provide to them by vendors of CAS packages. Some CAS comes with no supporting training package and materials. However, manuals do accompany CAS software bought with confusing tutorial (Michael et al 2016). Nevertheless, some CAS vendors do offer implementation and training on selected packages from their employees but most of them are IT vested without bookkeeping and accounting skills so don't train on the core aspect of using the CAS package to pass the double entry bookkeeping to generate trial balance and other statement of returns. The challenged has always been that there is little study in the selection of CAS to the benefit of SME business owners/managers in less developed countries. These risks and challenges faced by SMEs are gradually militating against the rapid adoption and 
implementation of CAS packages in Ghana. This research study is to understand the processes SME managers adopt to select CAS packages. It study seek to understand how they were assisted in the software if any to select the optimal CAS among the lots and to understand the depth of training provided them. The study also seeks to evaluate the main functional requirements features of CAS most favoured by SMEs in their quest to select the optimal CAS packages for implementation.

\section{Small and Medium Enterprises (SMEs) and CAS}

\section{LITERATURE REVIEW}

Businesses are regarded as Small and Medium Seized (SME), if it fulfils certain requirement ceilings for staff numbers, sales turnover value reflecting in its periodic statement of comprehensive income and financial position (European Union, 2003). The Ghana Statistical Service, 2012 (GSS), defines firms with more than 10 workers as SMEs. It could be seen from the definition and scope in table 1 that SMEs could have many workforces when it's operational activities expands according to Kayanula et al, (2000). The expansion of business activities in SMEs necessitates the need to have appropriate CAS package to process its large data set with ease and on time. The reason being that, it is now a requirement that SMEs business files periodic financial statements, Value Added Tax (VAT) returns, Employee Pay as You Earn (PAYE), Employee Pension Insurance (SNNIT) etc with the appropriate sub-agencies under the umbrella of the Ghana Revenue Agencies (GRA). Table 1 depicts different definitions for SMEs in different countries and this process has made the definition of SME incompatible and uniform as it does not have a uniform criterion across countries (Ayyagari et al. 2007). As a result of a non-convergence criteria and definition, SMEs definition in Ghana is largely based on the number of employees in the business set up as shown in table 1.

Table 1: Employee sizes used in defining micro, small, medium enterprises by a sample of IT researchers.

\begin{tabular}{|l|l|l|l|l|l|}
\hline AUTHORS & COUNTRY & MICRO & SMALL & MEDIUM & SME \\
\hline Burgess (2002) & Australia & $1-5$ & $1-20$ & & \\
\hline Igbaria et al. (1998) & New Zealand & & $20-100$ & & \\
\hline Chau (1995) & Hong Kong & & $1-49$ & & \\
\hline Ismail \& King (2007) & & & & & Malaysia \\
\hline Mathews (2007) & UK & & & & $1-200$ \\
\hline Wynn (2009) & $\begin{array}{l}\text { European } \\
\text { Countries }\end{array}$ & & & & $1-249$ \\
\hline Duxbury et al. (2002) & Canada & $2-9$ & $10-100$ & $100-500$ & \\
\hline $\begin{array}{l}\text { BharatBharati \& Chaudhury } \\
(2006)\end{array}$ & USA & $1-10$ & $11-100$ & $101-500$ & $1-500$ \\
\hline (Kayanula et al, 2000 & Ghana & & $1-10$ & & $>10$ \\
\hline
\end{tabular}

\section{Accounting Software Proliferation and selection}

Choosing CAS application has turned out to be amongst the largely critical choices for SMEs within the quick-shifting business sphere. Accordingly, the CAS package SMEs choose must best serve its existing problems and may directly be standardized to meet its upcoming requirements in favour of information, monetary, and also non-monetary statements. Choosing the correct CAS package is not easy. If a wrong CAS is chosen, the corporation will spend much time plus funds to purchase and put into practice an updated one. Choosing the inappropriate CAS will be an absolute catastrophe for SMEs, it may result in huge loss of money, and perhaps even insolvency. Hence, it's suggested that organizations must invest more in researching every aspect of CAS prior to decoding to buy it. Investing in CAS package is a critical entity's decision amid its lifespan considered to be the major important strategic choices (Venkateswarlu, 2010). 
According to Matzler (2007), looking for CAS package in the software market from the perspective of the SME owner / managers are like looking for a needle in a hay stack because they are overwhelmed with choice and information which disrupt accurate decisions to selecting the optimal CAS package among the best in the market. This phenomenon may be somewhat similar to what is expressed as 'consumer confusion' in marketing literature posited by Venkateswarlu et al. (2010). Heikkila et al, (2013) argues that SMEs managers have often been disappointed with their selected CAS application packages because they are either difficult to use or do not meet the needs of their company's financial accounts processing requirements. The other issue is that consultants/vendors also do not understand clients SMEs business processes so do recommend CAS products, even though costly, does not meet requirements specifications. Hence, Bernard, (2012), suggests that entities must have time to research more into every aspect of CAS prior to making a decision purchase. This he believes will mitigate the risks of selecting sub-optimal CAS packages. He again is of the view that acquiring CAS package is an essential aspect of IT projects and so must be given the needed attention necessary to enable successful critical strategic choices to be made regarding CAS selection (Bernard, 2006).

A phenomena known as condition known as 'resource poverty' has caused many SMEs to to objectively evaluate their operational environments to see they in practice need a CAS package and if so, what specific accounting software package should they purchase and how it can be installed and run on their computerised systems. Compare with larger business entities, SMEs don't benefit from objective advice from third parties (consultants) on selection and installation of CAS package. The lack of such useful and independent suggestions adds up to the risks of selecting wrong CAS package with increase cost overruns and installation failures. These can be a barrier to the implementation of IS/IT in SMEs In the nutshell, we realised that the absolute absence of advice and support activities in the selection and implementation of CAS application is a major challenge for SMEs in Ghana. We believe the National Board for Small Scale Enterprises (NBSSE) in conjunction with the Association of Ghana Industries can collaborate with Technical Universities in the Ghana to offer training and awareness for their member businesses to serve as a wakeup call in the selection of CAS packages and who to call should the need arises for implementation.

Figure 1 proposed CAS Package purchase Model

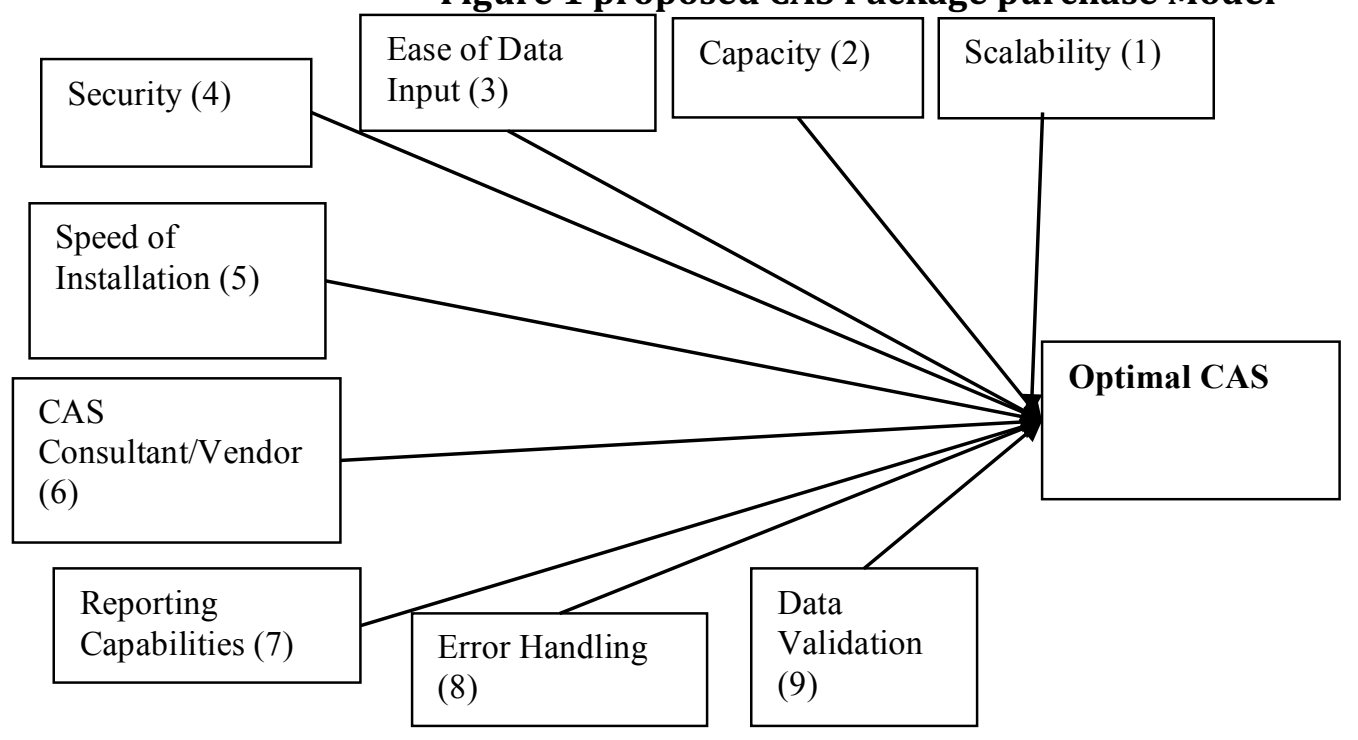


This framework serves as a basic guide to the selection of optimal CAS package to enable successful implementation and usage and accurate, timely and reliable financial reporting. The model may also be suitable to bigger business entities in their quest to selecting an appropriate and bigger CAS application such as ERP packages as it covers the basic functionalities expected of any AIS/CAS before a decision to buy. This does not guarantee an optimal performance of the package as the CAS originates from designers, programmers and vendors with varying skills and competencies in the software industry. Some CAS products may have all the qualities as demonstrated by the consultant/ vendor, yet may be generating error reporting's. Test running is recommended with dummy data to provide assurance before going live with real time data set. Configuration of the CAS package must begin with the SME's financial year. For example, the financial year may be twelve months from 1 st January to $31^{\text {st }}$ December each year. These requirements should be part of the installation and implementation process to enable statutory financial reports to be generated within this period (12 moths) for management to enable assessment of corporate performance and regulatory agencies for compliance evaluations.

\section{Scalability as a product}

The capacity of the CAS package to manage a growing number of users and higher loads of transactions is measured in software application. The CAS package must be embedded to process various accounting transactions depending on the degree of expansion of the entity. There are two variables of CAS product's scalability. A case point is that if the SME in say Haulage and Distribution now decides to run an abattoir service, the CAS package must be able to process accounts for each of the activities and then present an individual segment's accounts and finally a consolidated group accounts for the entire the SME as a corporate entity. It summary the CAS must have scalability function to accommodate more business activities as and when the need arises. There are two variables involved when considering scalability of CAS packages. The first variable is known as scaling up to determine if the software developer has varieties of CAS packages in varying capacities so that when the need arises for expansion, an entity can upgrade its existing accounting software to a more advanced version in a consistent, easy, and within budgets. The other aspect of scalability deals with series of queries such as: how flexible and quickly will the existing data will convert to the new CAS version from the other legacy platform; will the interface of the new software package remain the same after upgrade and fixing of bugs as the same interface significantly reduces the depth of training needed; the price incentives, if any, that are given to current SME customers who opt to upgrade; will reports and other customized features run when the old CAS package is upgraded or installed, or feature and data will be overwritten?,

\section{Capacity}

This module functionality determines the maximum number of customers, vendors, inventory and line items the CAS package can handle at a given time. Included in a single expenditure invoice, sales order, or purchase order it can handle at a given period within the financial year of business processing. The capacity functionality ensures that the CAS system components perform as efficiently as possible handle many business documents, both segmental and corporate processing's. Capacity enables description of system requirements and applications needed for any level of activity the entity is embarking on to ensure proper selection to meet processing specifications. The functionality make known the infrastructure components such as the operating systems and capacity required to be able to install and run the CAS package to deliver as required for the reporting business. The module Identifies and mitigate the risks of inefficiencies associated with under-utilized resources. It serves as a technical reference for CAS selection team members in their selection process to ensure that CAS selected functions satisfactorily in a cost-efficient manner. If CAS package selected is below capability, an SME 
manager would have to use other software applications, such as Excel spreadsheet and Access database management systems, to perform additional processing tasks the selected accounting software is incapacitated to handle (Randolph, 2003). This would come with additional cost of configuration and overhead expenses to the reporting entity.

\section{Ease of Data Input}

The reality is that even though reporting entity's managers may not need to have full understanding of their day-to-day routines, knowledge of how data interrelate amongst the modules of their processing activities boosts their capability to link data and information, performance, and strategy more successfully. Knowing how business processes at operations level integrate with data can assist them convert data into information for decision making purposes live and quickly. Accordingly, the worth of the data and information is only as good as its point of entry into the CAS application system. This implies that when managers across the company are examining diverse numbers to make decisions that will impact the business and the information and data does not add up, the responsibility for why these numbers are unacceptable lies at the point of entry of the data set and information into the operational CAS system. Data entry with errors and processing discrepancies are but some of the causes of error data which end up to drive an entity's decisions. As such SMEs would want to select CAS package which allows data and information to be entered quickly and correctly. The CAS should have the capacity to allow data set to be recorded at its rightfully defined filed according to the rules of the design view. A case in point, a field defined and programmed as salary with currency should not accept data as date of birth. This is because the data type for salary is different from salary. Any computerised system that accepts data anyhow is prone to reporting information with errors. The CAS must have the capacity to provide error prompt such as "Please this field is for Salary only" to enable the data entry person switch to the appropriate field. Full-screen editing must be provided as part of the CAS design so that errors could be corrected and resubmitted to overwrite previous data set. A help button must be seen on screen to support the data entry data entry user should he/she gets lost.

\section{Security}

This functionality in CAS measures the degree of protecting sensitive data and information reporting's. Security in computerised accounting systems have many levels such as the application level security, row-level (or multi-tenant) security, single sign-on security, user privilege parameters, Application level security is very clear-cut: enables the systems administrator to control the software package access on a per-user role, or per-user basis. It normally consists of a role-based menu system displaying different options to different users based on their assigned roles. It is important that every employee in a reporting entity be granted access to every application to enable accountability of activities performed on the CAS platform at any given time, For example, the SME manager might be granted access rights to all applications, while the accounting department can only access applications related to the accounting functions. The CAS application must be embedded with password functionality to protect data held on each module and sub-module. A CAS package with strong security may for example, allow a user to specify that the accounts payable clerk may only print cheques on Thursday afternoons beginning June 1 and ending August 30. CAS package with robust security feature must provide reporting trail to verify when a cheque run was performed and by whom. According to Eduardo et al, (2004), a weakness in a selected CAS package in terms of security vulnerabilities may have serious threats to the data and information held in the organisation. 


\section{Speed of Installation}

Installation of new CAS package is a major implementation project. A key issue that must be considered is quickly the new software package can be installed. As part of the installation, the CAS must be seen to producing the following:

1. Setting up the company, include the

2. Setting up your Customers \& Suppliers records (including opening balances)

3. Setting up your Nominal Ledger, (including opening balances)

4. Selling to customers on credit

5. Buying from suppliers on credit;

6. Customer \& supplier payments;

7. Cash receipts \& payments;

8. Bank account, petty cash \& recurring entries;

9. Reports \& routines;

10.9) Corrections \& adjustments

The next stage of the installation process is to request the selected CAS supplier to demonstrate his of his corporate such as may be accounts receivable and payable system. The SME manager/owner should present lists of definite coverage areas expected to be demonstrated by the vendor covering the following installation (Julie et al (2009):

1. Issuing and Managing Charges

2. Cash Receipting and payments

3. Other Reporting's such as VAT. SNNIT, PAYE, NHIS

4. Processing Transactions

5. Inquiry Options

The chosen CAS supplier is expected to take his time before the demonstration to query the entity about series of extensive questions regarding the SMEs needs. As part of the installation, team members must insist that the CAS supplier uses live software to prove the package functionalities and not some selected presentation software application or a "canned" demo that promote or raises just the CAS package generally. This is because the team want to see the software package performing in real action as part of the installation process to justify how it handles your specific activity needs (Randolph, 2003).

Since the installation is the heart core of the selection process, the CAS supplier should demonstrate the method of installation as part of its track record of implementing CAS system to run successfully on the operating system of the client. A list of SMEs the vendor has successfully installed same package should be requested for a call reference as customers are normally willing to share experiences valid tips to mitigate the risks of making similar errors they made. From a practitioner point of view, a customer who has implemented the CAS package for at least 13 months is appropriate as the selection team would want to see a yearlong usage to authenticate report generation within an accounting period.

\section{CAS Consultant/Vendor}

A software consultant can help considerably in selecting the appropriate CAS package for the SME business processing needs. CAS consultants may have special expertise in the purchasing through to the implementation process for many years. Although they charge fees, they can assist an SME organisation in ways such as: Evaluate and select the best CAS package for the SME business; save time and money during CAS system installing and subsequent training; Get the most out of the SME client's new system based on the system's capabilities and the SME business requirements. The presence of a reliable resident vendor is of strategic significance to the SME owner/manager as he or she will fall on him/her in times of technical help. In 
circumstances where the vendor does not reside within the community, there must be an arranged strategic contractual agreement to provide alternative service training and other technical support to the SME clients. Despite the compatibility of the CAS package to users' needs, SME users of the computerized accounting software still need the continued support from the consultant/ vendor (Ahmad.2005). Due to this, in deciding on CAS packages, an SME owner/manager should assure himself or herself that the vendor can be relied upon in times of disaster during real time usage of the CAS application; that he/she has got the skills necessary to meet the firm's (user) critical needs such as restoring data and information to its present state should there to any systems crashes either from the application's or the operating systems hardware end. These requirements are necessary to enable an SME manager/owner put in place an alternative mitigating circumstances to reduce the impact of the risks should in case the catastrophe is made known. The caveat is to be certain that the CAS consultant is not linked to any specific application vendor to also reduce the risks of getting into unfairness sales arena instead of an independent package evaluation.

\section{Reporting capabilities}

Information is useful in the current challenging business landscape. It is for this reason that any desiring accounting software being evaluated for purchasing is embedded with robust capabilities regarding reporting and analysis. Apart from helping users gain knowledge into critical financial transactions, reporting and analysis capabilities assist reporting entities comply with government regulation and business practices and requirements. The Ghana Revenue Authority for example mandates each reporting entity to file monthly (VAT) returns, (PAYE), (SSNIT) and end of year financial reports to enable corporate tax liability assessments by the Ghana Revenue Agency. Other stringent regulatory procedures are mounting responsibilities on business entities to ensure the accuracy and timeliness of published financial statements. Accounting is numbers in transactions. However, graphics display charts and other illustrative formats and forms, will be a useful means that can assist in generating trends analysis to management in a way that numbers alone cannot communicate to users. Using outmoded CAS package is like eating food that has passed its Selby dates; a risky idea that may end up giving severe nausea to patients. Tax laws and regulations relating to financial management practices keeps changing every moment, so it's imperative to select CAS application that can automatically updates itself as the directives come into full effect. There is also the probability that not all CAS application will perform exactly to match up with SME's business processing specifications. As a result, it is important that as part of the reporting, selected CAS package allows for easy modification of statements, forms, reports, help systems and other application features. The business world has moved to the Internet connectivity for dissemination and access to information as such, it is logical that CAS package selected follow the crowd. So in relation to reporting capabilities, the accounting software package selected should have a functionality and ability to send and receive digital documents and manage electronic fund transfers to suppliers and from customers etc. According to Heikkilä et.al, (1991), it must be embedded with query capabilities to identify for example, customers who have not made payments within a permissible credit period, using query language like SQL to support database technology in the CAS application.

\section{Error handling}

CAS application run-time errors could crop up as a result of errors in the design process, coding unawares, hardware failures, and many other events which may affect the processing performance of the accounting software package. Although you cannot anticipate all possible errors, the accounting software can be programmed to handle certain kinds of errors meaningful to the CAS application. The software selected must embed with a mechanism 
known as exception handling to enable SMEs "bulletproof" the selected CAS application so that it can continue operating in the presence of errors.

This error functionality in CAS determines ability to prevent unbalanced transactions. It is also able to stop and prompt users from deleting or otherwise losing important data which is previously held in the CAS package. The CAS application must provide detail audit trail for all transactions auctioned during a period from initiation to completion to provide error reports for the CAS running errors to enables traces to be made to fix and patch bugs by the vendor consultant should the need arise However, computers do lack capability to judge, as they cannot detect unanticipated errors users commit. This is because the software to detect and check errors is a set of programmes for known and anticipated errors only. (Accountancy, 2013)

\section{Data validation}

This determines how good the selected CAS is at preventing mistakes from being recorded into the system. The CAS program should check for errors such as duplicate customers and vendors details, inaccurate item numbers, and unreasonable amounts or dates formats. The data validation capability ensures the accurate and authorised data allowed to enter the CAS system. This is known as input controls to ensure only valid data within certain authorised threshold and limits are allowed to be process by the computerised accounting to assure of information reliability. Validation capacity in the CAS application quickly identifies and classifies exceptional data for further investigation prior to resubmitting for processing. This validation is made by the 'Error Detection' and 'Error Correction' procedures embedded within the CAS software and so must be seen to operational with a test of wrong data to evaluate the selected CAS integrity. This function is a controlled process, whereby live input data is compared with a predetermined standard to detect and eliminate errors before data move into the transaction processing stage. A powerful CAS package embedded with error correction message and procedures do offer suggestions on-screen as a prompt on how to enter the correct data input by directing the user to see his or her systems administrator for assistance on that data input (Mpofu, 2011). A CAS validation capability function should be able to notify the data input user of unusually high number of unit prices for certain types of inventory items and then offer a valid choice of actions along with the warning note.

\section{Audit Trail}

The computerized accounting software package must be seen to be embedded with a capability to hold documents in the computer files, and other records that are needed for examination during a computerized audit, to determine how transactions are handled by an SME business owner or manager. An audit trail in a strictest sense can either be a paper or automated based trail that supports documented history of a transaction within a company. The audit trail embedded as a module in the CAS will enable an IS/IT auditor to trace the financial data from the general ledger to the source documents such as invoices, receipts, voucher etc view the full process of a given transaction from input through to output generation. The presence of a reliable, non-complicated workable audit trail function in a computerized works environment is an indicating of solid internal controls compliance instituted by a business entity, which can form the basis of objectivity in the CAS system. Alternatively, an audit journal with missing documentation is a clear indication that an enity system is not adhering to proper and laid down accounting practices. The audit trail should be seen to include the chronological list of steps that are taken to initiate a transaction processing on the CAS system to its completion. An audit trail must be activated by default and the recorded trails must not allow for deletion and modifications during storage at any one time. Any CAS package whose audit trail functions could be modified is a recipe for fraud and should not be selected. The integrity of the audit 
trail must be part of the demonstration process by the vendor supplier during the installation process.

\section{THE RESEARCH METHODOLOGY}

This research study adopts the quantitative method to understand how SMEs select their CAS packages. As a result, a structured questionnaire was prepared to aid in data collection for the study. The questionnaire covered the following areas as proposed in figure 1: scalability, capacity, ease of data input, security, speed of installation, consultant/vendor availability, reporting capabilities, error handling abilities and data validation and Audit trail. The questionnaires were made up 20 to employees of the sampled SME entities. The survey instruments were sent to 150 selected SMEs in the Kumasi Metropolis of Ghana who were willing to part of the study. The need and importance SMEs attached to the study by the Association of Small and Medium Enterprises (ASMEs) chapter in Kumasi prompted all their selected member businesses to all respond to the questionnaire sent to them. It was also successful because we went to each SME business with a letter of introduction from their association's head office. Demographic data were not collected as the researchers assumed that respondents including managers, owners and staff are of legal age of majority (18years) before being allowed to engage in business establishments and also being employed by these SME businesses. The researchers rather concentrated on the issues confronting SMEs in the selection and implementation of CAS packages instead.

The selected member SMEs are in varied business set ups from wholesale to retailing, dealing in Auto Parts Imports, A shopping Mall, Haulage and Distribution Distributor of Building Hardware, Abattoir Services , Poultry Farming located within the strategic clustered locations in the Kumasi metropolis of Ghana. The research instrument was actually tested on a pilot basis to ensure consistency and reliability by occasional adjustments to fit the purpose for which it was intended. In the course of analysing the data, descriptive analysis, Excel was used in the preparation of the data and analysis. The distribution of the sampled SMEs according to their respective numbers and merchandise are depicted in table 3.1 below:

\begin{tabular}{|l|r|r|}
\hline \multicolumn{3}{|c|}{ Table 3.1 Distribution of SMEs } \\
\hline Type & No & \multicolumn{2}{l|}{$\begin{array}{l}\text { Relative } \\
(\%)\end{array}$} \\
\hline Auto Parts Imports & 21 & 14 \\
\hline A shopping Mall & 15 & 10 \\
\hline Haulage and Distribution & 23 & 15.33 \\
\hline Distributor of Building Hardware & 44 & 29.33 \\
\hline Abattoir Services & 12 & 8.00 \\
\hline Poultry Farming & 35 & 23.33 \\
\hline Total & 150 & 100.00 \\
\hline
\end{tabular}

Approximately 30\% of the participating SMEs are found in the distribution of construction and building hardware. While approximately 24\%,16\%,14\%,10\% and $8 \%$ in poultry farming, haulage and distribution, auto parts distribution, shopping marts, and butchery and abattoir services respectively are operating in the sampled SME sector.

\section{DATA ANALYSIS AND DISCUSSION}

Figure 4.1 seek to understand the position of sampled staff within the selected SME business so as to determine the level of relativity in terms urgent need to implement CAS package as the 
information age requires. The nearer the personnel are found in financial data set position determines his or her awareness of the need to speed up the generation of financial returns to management and statutory agencies for their decision makings on a timely basis.

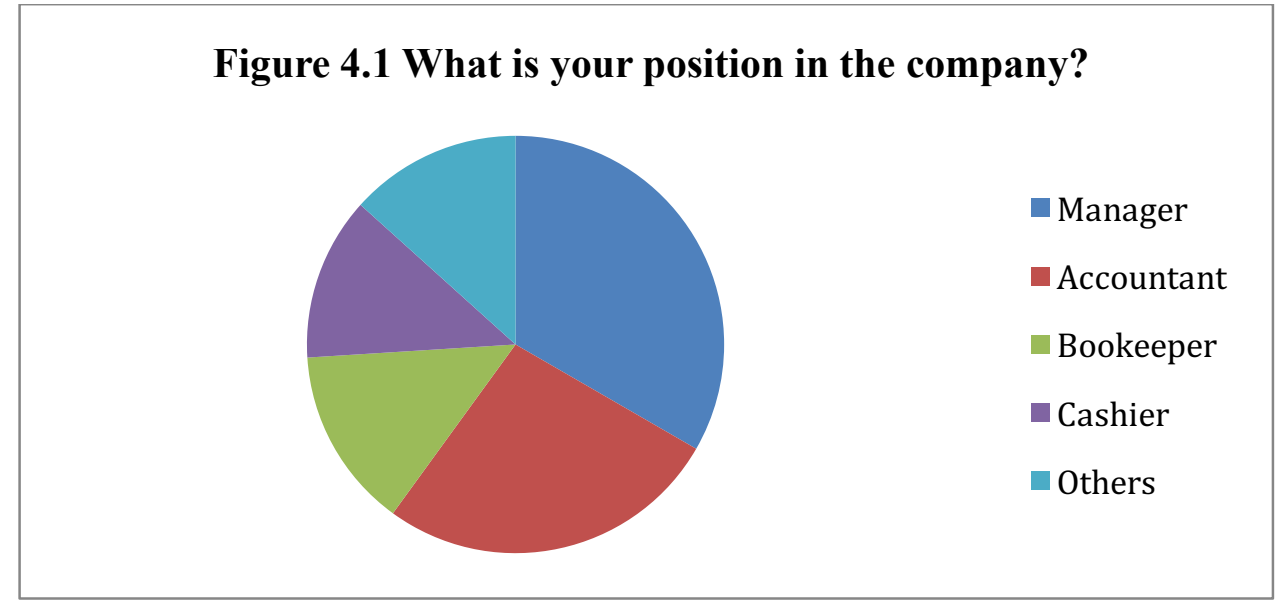

(Source: authors own field work, 2017)

From the report above it could be seen that managers within the sampled SMEs in Ghana takes a chunk of the position (33.33\%). This is followed by Accountants (26.67\%), bookkeepers (14\%), and cashiers (12.67\%) respectively. It implies that these personnel's are aware of the need to implement CAS due to the need to meet time lines in the submission of reports to relevant authorities like the Ghana Revenue Authority for tax assessments on time to avoid penalties and blacklisting.

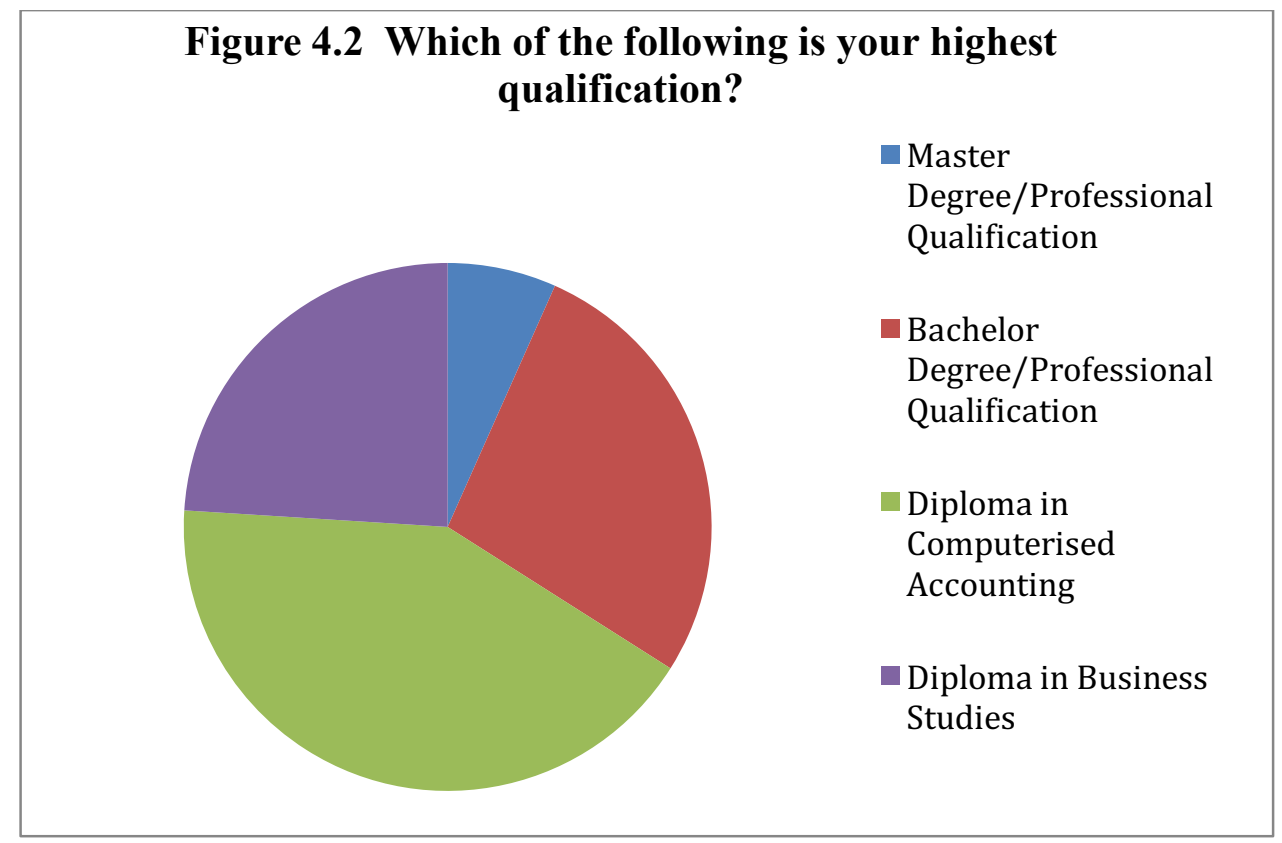

(Source: authors own field work, 2017)

Figure 4.2 portrays the level of education of staff personnel within the sampled SMEs entities. The aim is to determine their level of training so far as education in recording, processing and the generation of financial reports are concerned. The results showed that Diploma in computerised accounting personnel rank high with $42 \%$ followed by Bachelor Degree with professional qualification (27.33\%), Diploma in Business Studies (24\%) respectively. MBA with professional qualification rank low (6.67\%) because most of them are hired in bigger 
organisation. Some of these high academic and professional qualifications holders we understand were owners and managers of some of the SME organisations under study. Diploma in computerised accounting holders were high because the Kumasi Technical University in collaboration with Sage university in Canada have developed a training centre to offer training programme in accounting with computing to help SMEs keep Proper books of accounts using computerised accounting software packages.

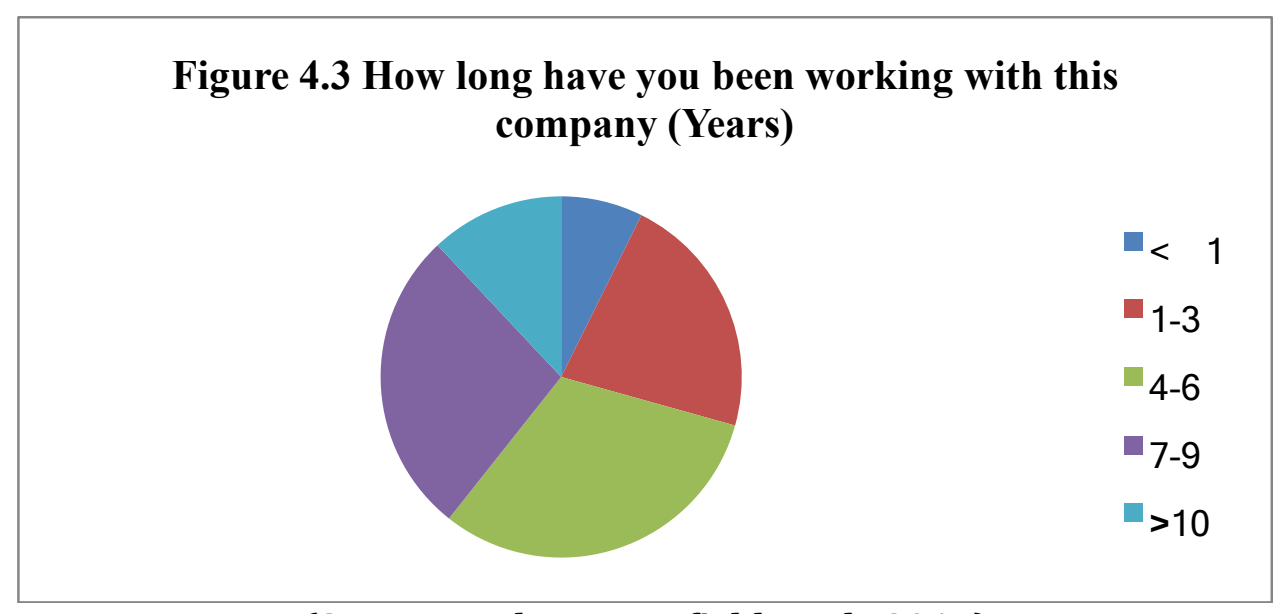

(Source: authors own field work, 2017)

Figure 4.3 depicts the length of experience staff personnel have had in their respective SME entities. The objective is to understand the years of involvement in the preparation of financial statements and the inherent challenges confronted with. The chart shows that most staff have worked in their respective SME organisations ranging between the ages of 4-6 years (33.33\%) followed by 7-9 years (27.33\%). The higher the level of experience in working with organisation coupled with the academic and professional depicts the competency and efficiency of the staff so far the selection and implementation of CAS package is concerned.

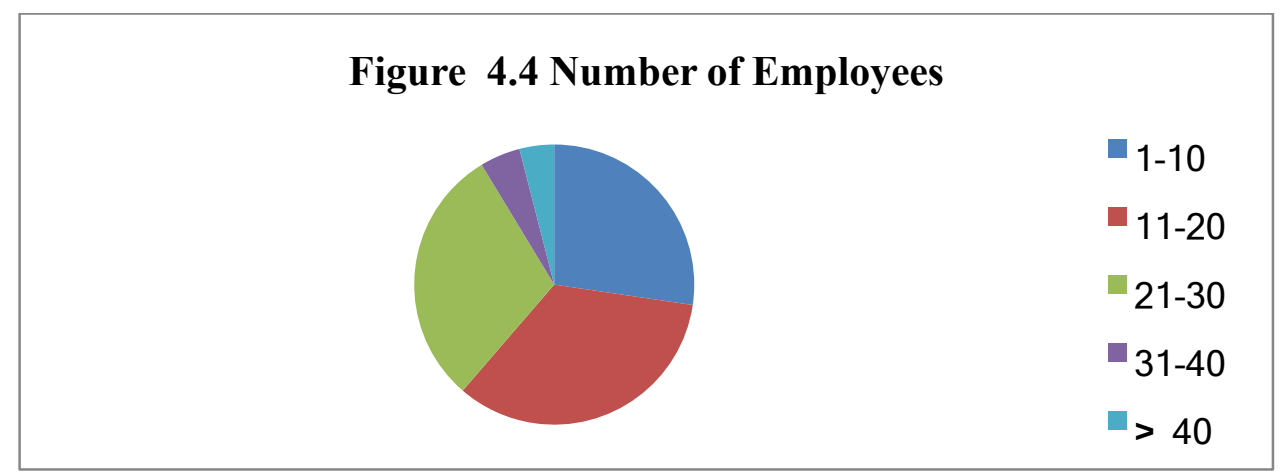

(Source: authors own field work, 2017)

Figure 4.4 depicts the number employees in the sampled SME entities. The aim is to identify the level of activities in these organisations. The higher the employees means bigger level of operations which warrants the implementation of CAS packages for payroll, Social Security and National Insurance Trust (SNNIT) Employee Pay as You Earn (PAYE), VAT returns and other management and statutory returns. It could be seen that employees with the rages of 11-20 dominated employment in SMEs followed by 1-10 and then 21-30 respectively. This also confirms Kayanula et al, 2000 assertion that SMEs in Ghana by definition ranges from 10 and above. 


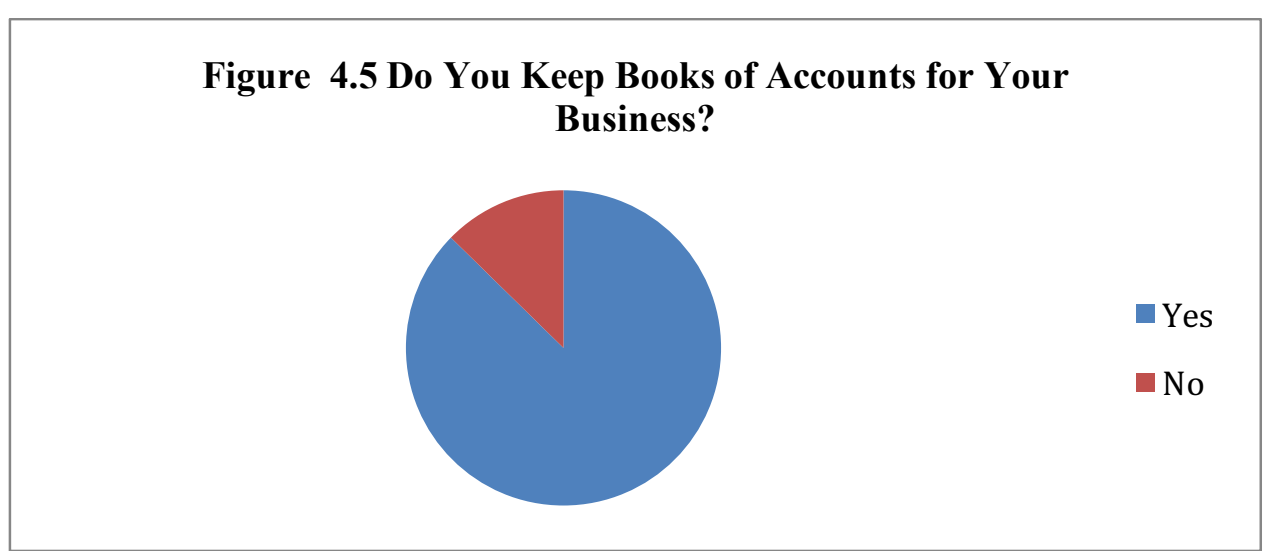

(Source: authors own field work, 2017)

The above shows the results of those SMEs that keep proper books of accounts as against those who don't keep it in Kumasi metropolis of Ghana. The massive increase in keeping of accounts is the adherence of government's invoking of section 123 of Ghana's Companies Code (1963), Act179 which makes it mandatory for all reporting entities such as SMEs to ensure that proper books of accounts are kept in the ordinary course of business transactions with regard to their statement of comprehensive income and financial positions and any changes that have occurred. The ministry of finance issued a directive through the Ghana Revenue authority to enforce compliance on the part of SMEs. This is a clear indication that indeed SMEs are complying with the directives.

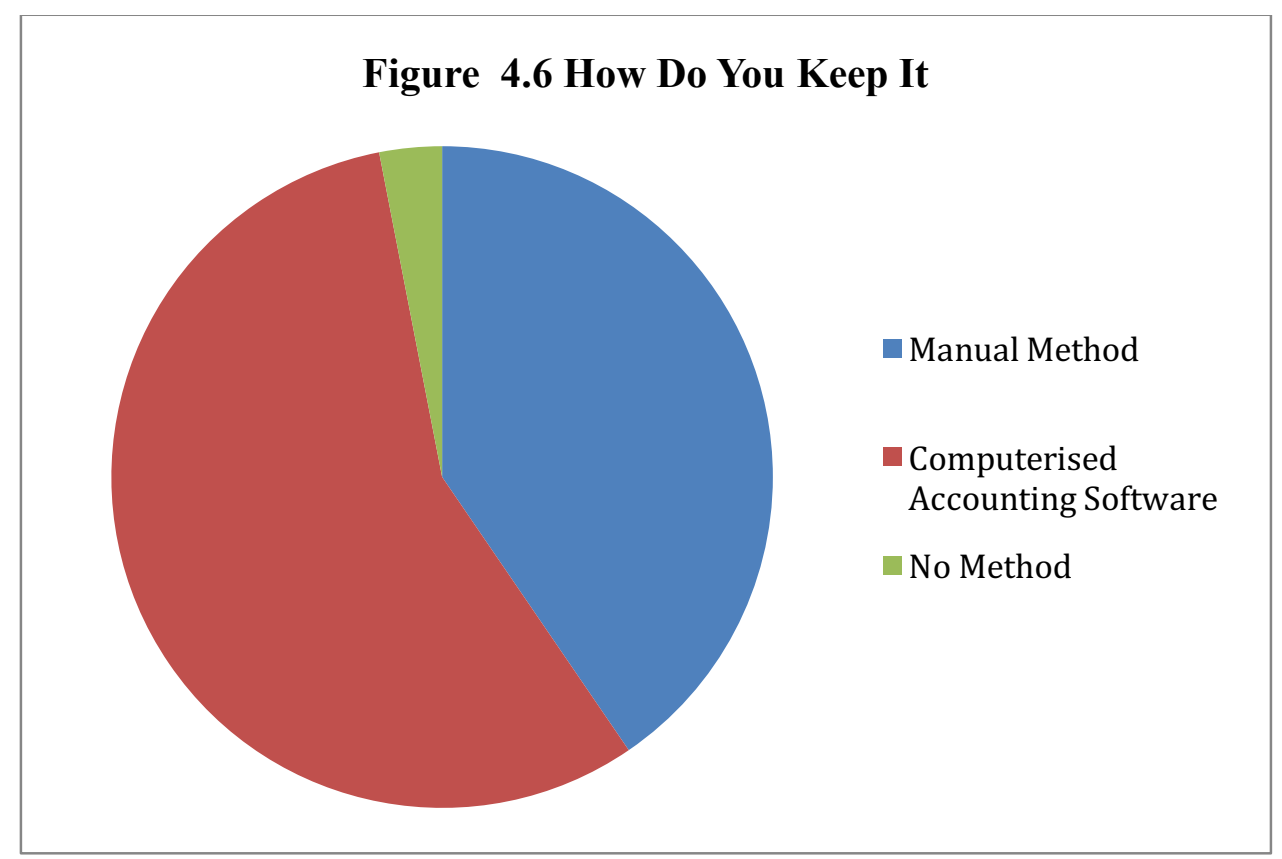

(Source: authors own field work, 2017)

Figure 4.6 portrays how SMEs who responded to keeping accounts prepare their financial statement. 56.49\% representing 74 SMEs responded using CAS in recording, processing and generating of financial statement. This is followed by $40.46 \%$ representing 53 SMEs who don't use CAS in the preparation of financial data. The growth in the use of CAS is stemmed from the fact that Kumasi Technical University in collaboration with the Association of Small Scale Business in Ghana (ASBG) supported by Sage University Canada are training students at the Diploma level about the use of Sage products to keep accounts for SMEs within the Kumasi Metropolis. A further investigation into why SMEs still use the manual method to keep accounts revealed the frustration SMEs goes through in selecting an appropriate CAS packages 
for their respective businesses. This also confirms Jones (2002) assertion that choosing a CAS package in many ways is like choosing a life partner (man or woman) which comes with benefits such as affordability and high functionality but with potential complexities such as risks, uncertainties and dependency posits Venkateswarlu, (2010).

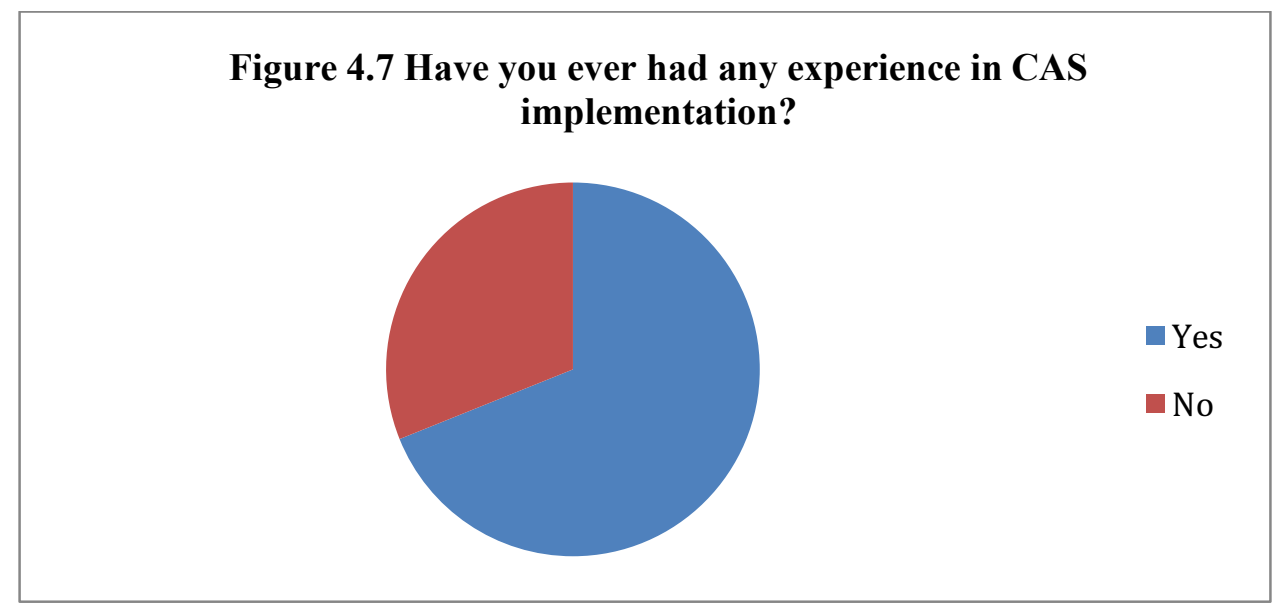

(Source: authors own field work, 2017)

Figure 4.7 depicts the level of experience staffs who use CAS to process financial data have gained in the implementation of the package. The more the person has been involved in the implementation the lower the risks of selecting the wrong CAS package in the software market. $68.92 \%$ representing 51 employees confirmed being part of the implementation process and $31.08 \%$ representing 23 employees responded in negative. Pressed further those who responded to No said they are not call upon to part of the selection and implementation team when their SME managers desire the implementation CAS Packages. They only become aware when it has been installed and running with little or no training forcing them to study CAS package them using confusion manual provided by the CAS vendor. This confirms a statement from the introductory part of this research that some SME owners complained that they do not understand how CAS works because of little or no training provided to them by vendors of CAS packages. Some CAS comes with no supporting training package and materials. However, manuals that do accompany CAS software purchased are confusing in tutorial.

Figure 4.8 shows the results when respondents who have involved in the implementation of CAS package were asked if they had any software package for selection when they went to the software market. $66.67 \%$ representing 34 responded in a negative that they had no idea which CAS package to purchase while $33.33 \%$ representing 17 said they were aware of the software they were going to look for in the software market. The lack of information on CAS packages in Ghana has contributed to the lack knowledge of specific CAS packages in the market. Pressed further, those who knew of the package prior to selection had the chance to see a demonstration from rival SMEs in the same industry and their performance. This confirms Michael (2015), suggestion that "it is worth noting is to seek information from similar neighbour SME firm, who has made a successful implementation of an AIS/CAS package and usage. If an SME manager is able to receive a network of information of this nature, then decision making becomes much easier so far as selection of CAS package is concerned". 
Figure 4.8 Did you have any CAS package in mind when you were going to the software market?

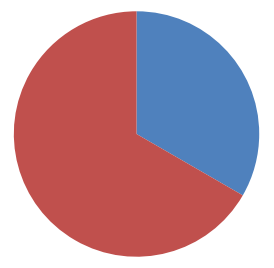

Yes

$\square$ No

(Source: authors own field work, 2017)

Figure 4.9 aimed to understand if the personnel in the implementation process of CAS indeed were confronted with many CAS packages such as Sage Pastel, Sage Peachtree, Sage Line 50, Sage Line 300 ERP, Mine Your Own Business (MYOB), Quick books, Tally, Money works, Quickens, SAP, PeopleSoft, and Oracle, ADP, Great Plains, JD Edwards, and other locally developed ones in the market. The overwhelmed response signifying yes $(70.69 \%)$ confirms the proliferation of CAS packages in the software market in Ghana with varied information. Those in the negative response indicated that the CAS packages were brought to attention at the work place for installation and evaluation over a certain trial period for either acceptance or decline. They realised it was good for them at the end of the trial period and so did not bother to go to the software market.

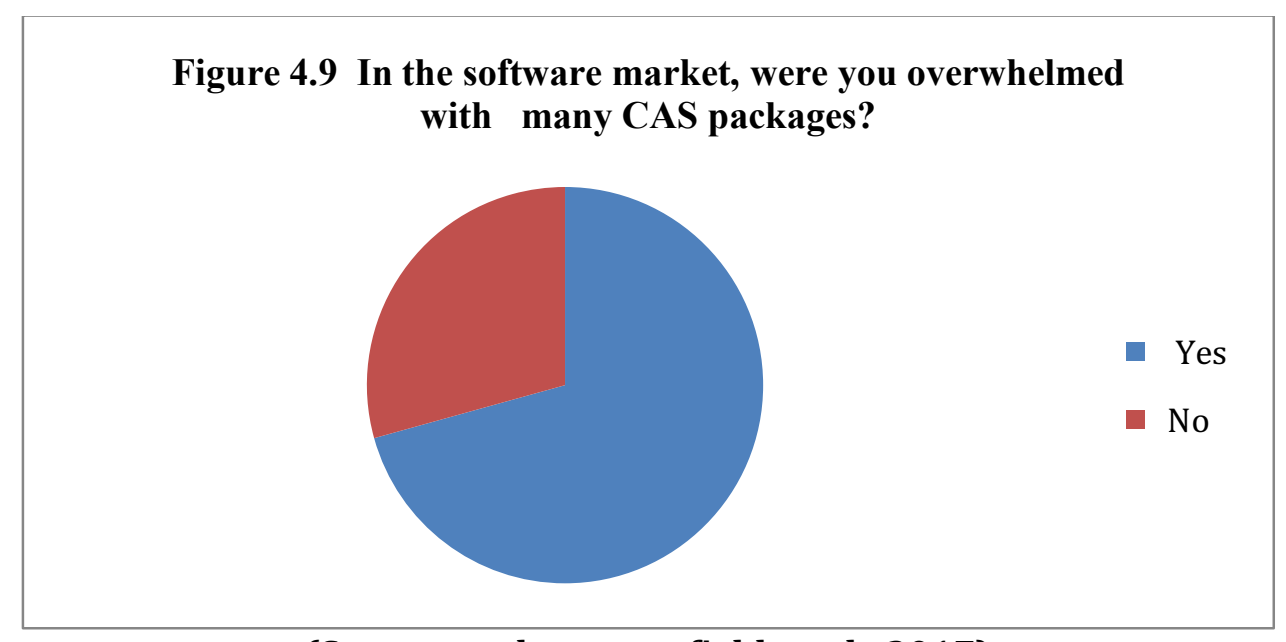

(Source: authors own field work, 2017)

Figure 4.10 shows the results of respondents who were overwhelmed with many CAS packages in the software market. The aim is to understand the personalities which assisted them make the best selection of their choice among the lots. The results showed that advice from similar SMEs enabled them make the rightful decision in the selection process (51.22\%) followed by IT Vendor support through to advert. IT vendors from years of experience are able to tell which software best fits a particular reporting entity. Chartered accountants are able to provide the needed software selection as results of working for many client SMEs. However according to Michael, (2015) is of the view that an accounting firm should not be used as a consultant to the small businessperson seeking a software package as they may connive with the software vendor to sell at a commission certain quantities of CAS packages so may force an SME client to buy a package which may not business processing needs. The low level of adverts shows that software developers don't advertise the presence of CAS packages in the market. This goes to confirm 4.8 that most of the respondents are ignorant of any CAS package availability in the country. 


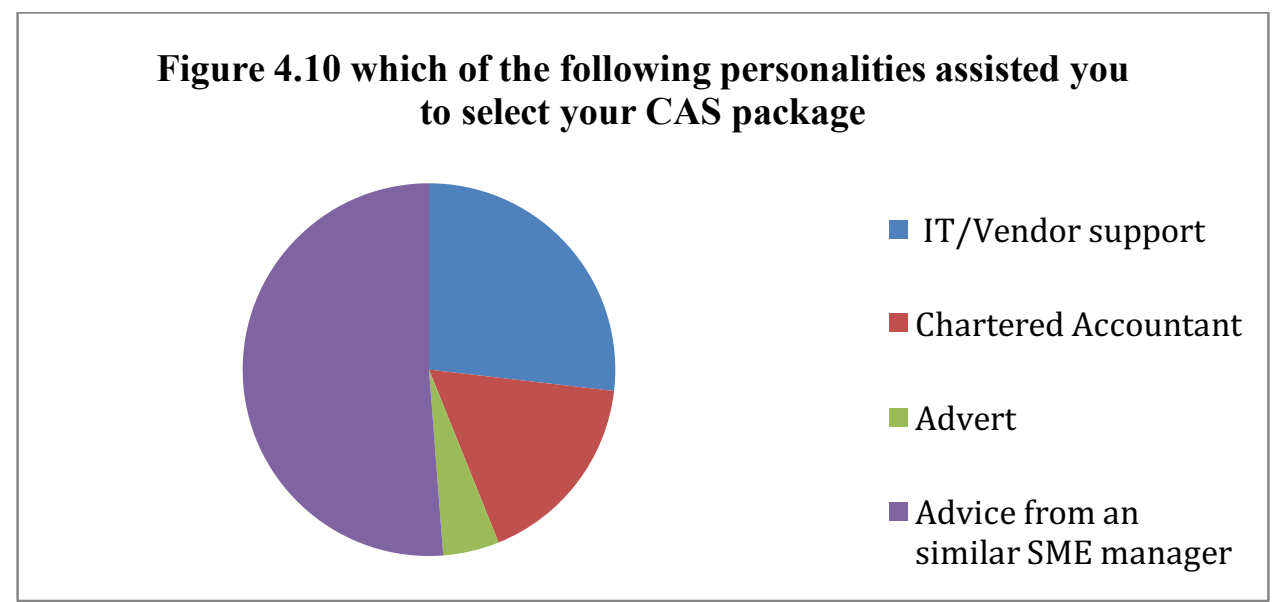

(Source: authors own field work, 2017)

Figure 4.11 is aimed at understanding if respondents in figure 4.10 have some basic functionalities of CAS in mind prior to going to the market to buy the package from software vendor suppliers. The result indicates that there was no aforementioned knowledge about the functionalities to look for in the selection of CAS package which constituted about $71.61 \%$ of respondents. Those who responded to yes made mention of Functionality, Consumer needs, Present needs, Future needs, CAS needs, Pricing \& Financing option, Maintenance/Upgrades/Patches, Flexibility, Implementation, IT Environment/ Security and Vendor credentials which were way above the basic fundamental features that have to be met on any selected CAS before proceeding to purchase it. All these thoughts are brilliant yet, until some basic determinants are met one may choose the wrong CAS package.

Figure 4.11 Did you have in mind any feature/functionalities of CAS to aide you to select the best in the market?

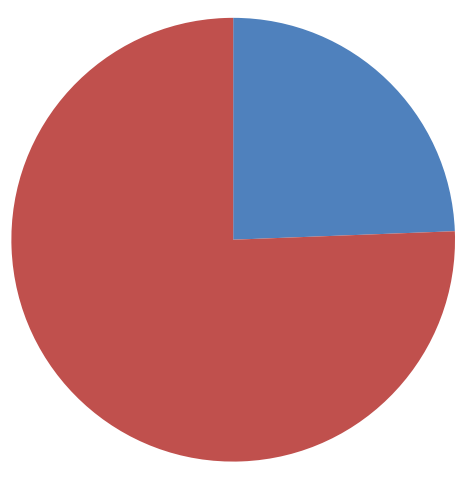

Yes

No

(Source: authors own field work, 2017) 
Figure 4.1 which of the following basic features/functionalities did you consider before selecting CAS package

\begin{tabular}{|c|c|c|c|c|c|c|c|c|c|c|}
\hline SMEs & $\begin{array}{l}\text { Scalabi } \\
\text { lity }\end{array}$ & $\begin{array}{l}\text { Capac } \\
\text { ity }\end{array}$ & $\begin{array}{l}\text { Ease } \\
\text { of } \\
\text { data } \\
\text { Input } \\
\end{array}$ & $\begin{array}{l}\text { Securi } \\
\text { ty }\end{array}$ & $\begin{array}{l}\text { Speed of } \\
\text { Installation }\end{array}$ & $\begin{array}{l}\text { CAS } \\
\text { Consultant } \\
\end{array}$ & $\begin{array}{l}\text { Reporting } \\
\text { Capabilities }\end{array}$ & $\begin{array}{c}\text { Erro } \\
\mathbf{r} \\
\text { Handl } \\
\text { ing } \\
\end{array}$ & $\begin{array}{c}\text { Data } \\
\text { Validat } \\
\text { ion }\end{array}$ & $\begin{array}{c}\text { Audit } \\
\text { Trail } \\
\end{array}$ \\
\hline Auto Parts Imports & 7.00 & 5.00 & $\begin{array}{r}8.0 \\
0 \\
\end{array}$ & 7.00 & 11.00 & 4.00 & 7.00 & 7.00 & 9.00 & $\begin{array}{r}6.0 \\
0 \\
\end{array}$ \\
\hline A shopping Mall & 6.00 & 4.00 & $\begin{array}{r}7.0 \\
0 \\
\end{array}$ & 9.00 & 7.00 & 12.00 & 13.00 & 5.00 & 5.00 & $\begin{array}{r}6.0 \\
0\end{array}$ \\
\hline $\begin{array}{l}\text { Haulage and } \\
\text { Distribution }\end{array}$ & 9.00 & 7.00 & $\begin{array}{r}5.0 \\
0\end{array}$ & 6.00 & 8.00 & 9.00 & 8.00 & 5.00 & 4.00 & $\begin{array}{r}11 . \\
00\end{array}$ \\
\hline $\begin{array}{l}\text { Distributor of Building } \\
\text { Hardware }\end{array}$ & $\begin{array}{r}16.0 \\
0 \\
\end{array}$ & $\begin{array}{r}15 . \\
00\end{array}$ & $\begin{array}{l}14 . \\
00\end{array}$ & $\begin{array}{r}13.0 \\
0 \\
\end{array}$ & 6.00 & 7.00 & 5.00 & 9.00 & $\begin{array}{r}13.0 \\
0 \\
\end{array}$ & $\begin{array}{r}6.0 \\
0 \\
\end{array}$ \\
\hline Abattoir Services & 0.00 & 5.00 & $\begin{array}{r}3.0 \\
0 \\
\end{array}$ & 4.00 & 5.00 & 5.00 & 4.00 & 3.00 & 6.00 & $\begin{array}{r}7.0 \\
0 \\
\end{array}$ \\
\hline Poultry Farming & 3.00 & 5.00 & $\begin{array}{r}4.0 \\
0 \\
\end{array}$ & 2.00 & 4.00 & 4.00 & 4.00 & $\begin{array}{r}12.0 \\
0 \\
\end{array}$ & 4.00 & $\begin{array}{r}5.0 \\
0 \\
\end{array}$ \\
\hline Total & $\begin{array}{r}41.0 \\
0\end{array}$ & $\begin{array}{l}41 . \\
00\end{array}$ & $\begin{array}{l}41 . \\
00\end{array}$ & $\begin{array}{r}150 . \\
00\end{array}$ & 41.00 & 41.00 & 41.00 & $\begin{array}{r}41.0 \\
0\end{array}$ & $\begin{array}{r}41.0 \\
0\end{array}$ & $\begin{array}{l}41 . \\
00\end{array}$ \\
\hline
\end{tabular}

(Source: authors own field work, 2017)

Regarding table 4.1 we surveyed SMEs according to their type of business using this approach to establish their staff personnel's insights into the basic functionalities of CAS application and their features that are perceived to be most optimal in the selection their CAS application packages. The high frequency of occurrence indicates the importance they attached to the CAS feature in their selection of CAS software supplier which highlighted in bold. Our next area of the investigation was to ascertain the main factor categories considered to be the most significant to SMEs in their desire to implement CAS application package. The outcome of this study is showed in Table 4.2. As depicted in Table 2, SMEs rated Ease of Data Input as the optimally significant general factor category in their CAS software selection process The next essential basic feature for SMEs CAS selection was the support expected from the vendor consultant of the CAS package in terms of training, upgrade and other maintenance into the foreseeable future of the CAS usage. SMEs are very interested in audit trail to track down activities performed on the CAS platform during and after working hours for authentication and fraud deterrence as well as prevention. Users are concern with speed of installation of the CAS package with all the related modules needed to execute the financial data processing and the generation of the needed reports. This confirms reports from SMEs that some of the locally produced CAS packages are difficult to run on the operating systems hardware. The ranking goes down to error handling which was least selected. However, any CAS package that does not have this capabilities embedded will accept any data format such as date of birth as salary field. The results will be a disaster for SMEs in their report generation as there will errors. Although it's been low, many of the CAS packages examined seemed to contain this basic feature. 
Table 4.2 Most Essential CAS Attributes

\begin{tabular}{|c|c|c|c|}
\hline \multirow{2}{*}{$\begin{array}{l}\text { Ranking Scale: } 1= \\
\text { Most important; } 6= \\
\text { least important }\end{array}$} & \multicolumn{2}{|c|}{$\begin{array}{l}\text { To Users in Selecting } \\
\text { Software Packages }\end{array}$} & \multirow{2}{*}{$\begin{array}{r}\text { Mean comparison } \\
\text { T-Statistic } \\
* * * \mathrm{p}<.001 \\
* * \mathrm{p}<.01 \\
* \mathrm{p}<.05 \\
\end{array}$} \\
\hline & Mean(n=25) & Ranking & \\
\hline Scalability & 2.386 & 8 & $3.661^{* * *}$ \\
\hline Data Validation & 2.070 & 7 & $3.179^{* * *}$ \\
\hline Ease of Data Input & 1.298 & 1 & $2.676^{* *}$ \\
\hline Security & 1.961 & 6 & $3.009^{* *}$ \\
\hline $\begin{array}{l}\text { Speed of } \\
\text { Installation } \\
\text { CAS }\end{array}$ & 1.672 & 4 & 0.734 \\
\hline Consultant/Vendor & 1.312 & 2 & -0.438 \\
\hline $\begin{array}{l}\text { Reporting } \\
\text { Capabilities }\end{array}$ & 2.415 & 9 & $3.446^{* *}$ \\
\hline Error Handling & 2.561 & 10 & \\
\hline Capacity & 1.801 & 5 & $3.597^{* * *}$ \\
\hline Audit Trail & 1.331 & 3 & $-3.074^{* *}$ \\
\hline
\end{tabular}

Figure 4.12 was aimed at determining if training was given to SMEs after they have selected a best-fit CAS supplier. The results depict less training offered to those who selected no representing 63.41\% and yes representing 36.59\%. This confirms Michaels, (2015) position that "some SME owners complained that they do not understand how CAS works because of little or no training provide to them by vendors of CAS packages. Some CAS comes with no supporting training package and materials. However, manuals do accompany CAS software bought with confusing tutorial"

\section{Figure 4.12 Were you given training during and after the} CAS implementation process by the supplier?

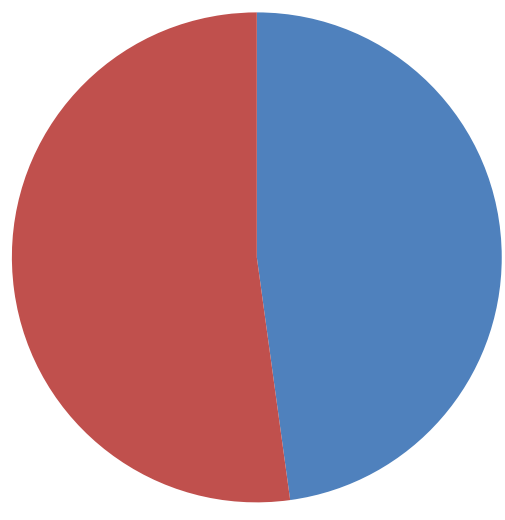

- Selection very quick

The Implementation and Installation very Quick

Figure 4.13 was to the awareness of participants regarding the automation of CAS packages prior to implementation. The results are depicted below with varying insights. 


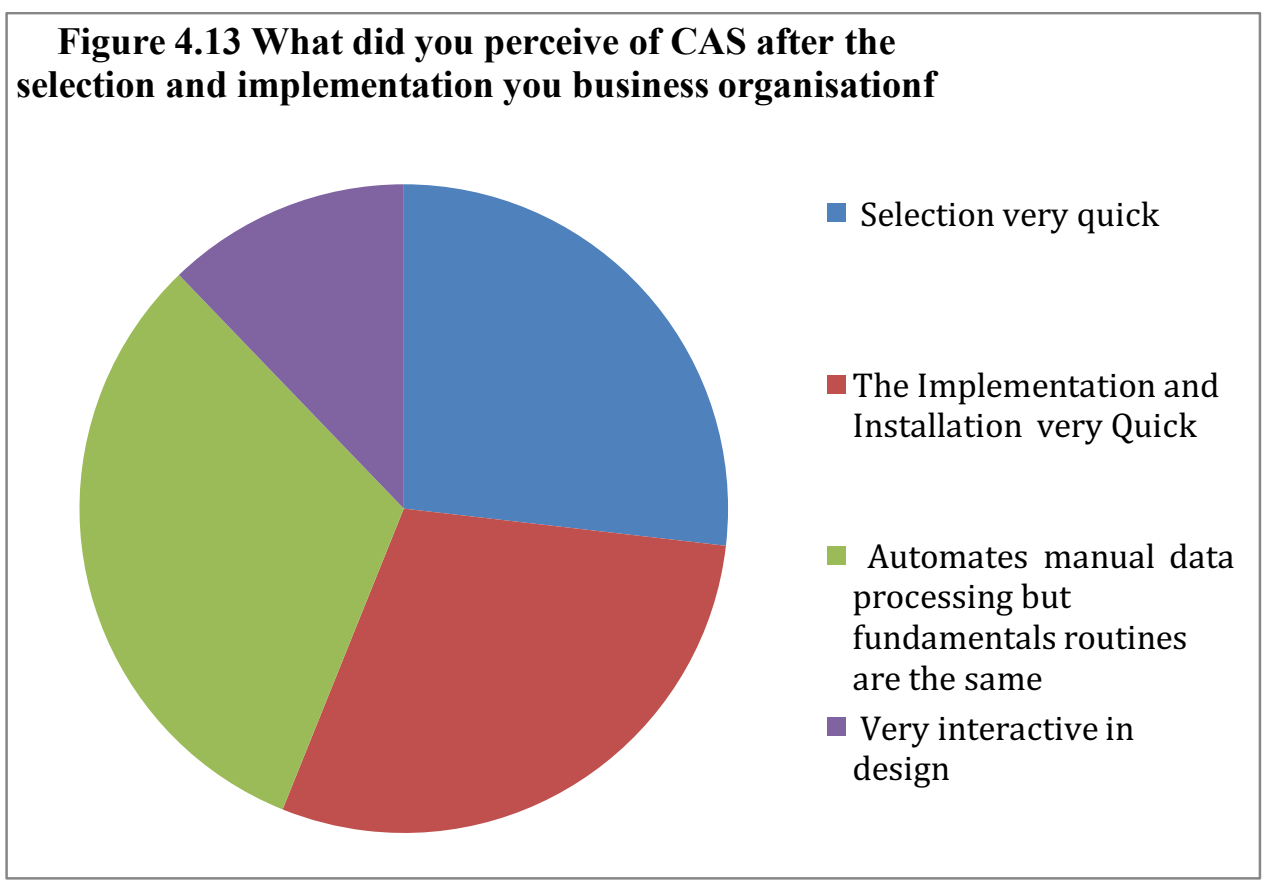

Finally figure 4.14 was used to assess participant's awareness of the CAS packages selection and implementation. The outcome is showed below:

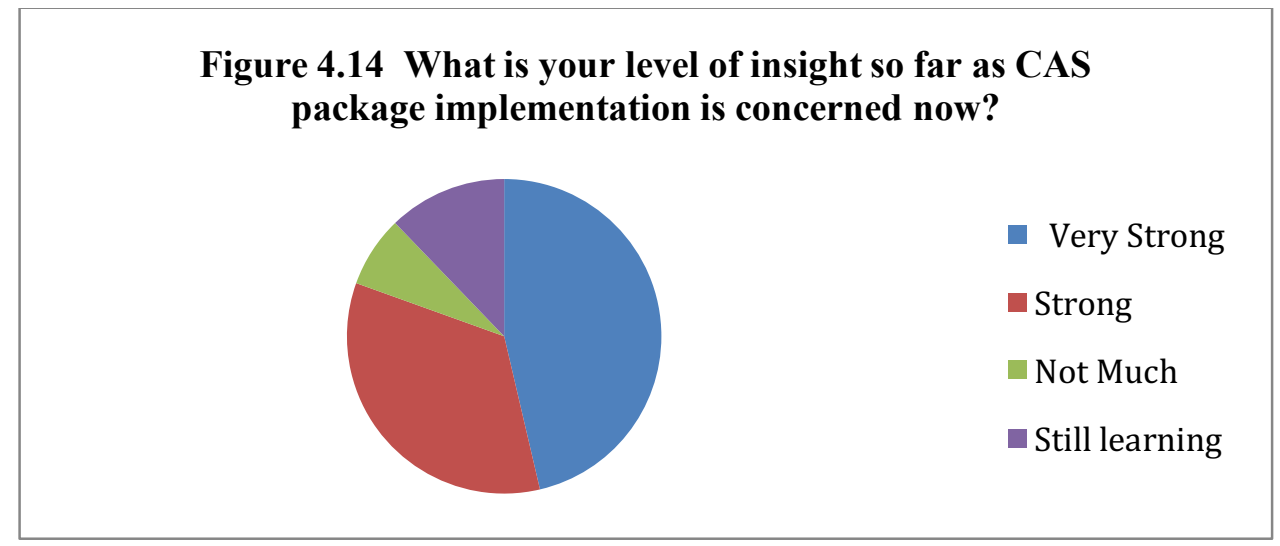

On the whole it could be seen that the level of awareness has increased among SMEs in Ghana which could be attributed to government policy of directing all SMEs to computerize their financial data processing. The other responses although not significant so far as the investigation is concerned could be significant in general sense.

\section{CONCLUSION AND RECOMMENDATIONS}

To put into operation a CAS application successfully, it is imperative to select a CAS application which can be compatible with the special requirements needs and demands of the SME organization. The purpose of this research study was to understand how SMEs select their CAS packages amongst the lots in the software market and also understand the sort of supports received from vendors in terms of trainings and other after sales services. It was also explain theoretically our proposed model which may assist SMEs selects an appropriate CAS vendor supplier. We looked into Scalability, Data Validation, Ease of Data Input, Security issues surrounding the CAS package, Speed of Installation of the CAS package on the organization's operating systems, Consultant/Vendor support with training and periodic upgrade and maintenance, Reporting Capabilities of the CAS package to meet statutory and management need, Error Handling abilities of the CAS to enable the rightful data to be entered in its required fields etc, Capacity of the CAS to enable other trading activities to be configured and to enable 
consolidated accounts to be prepared for operational activity and Audit Trail capabilities to track down and monitor activities of each assigned staff on the systems for effective internal control purposes. The study has revealed that SMEs of our sampled companies are more interested in CAS packages which are easy to use so far as data input and vendor support are concerned which is typical among our framework's proposed criteria's in selecting a CAS supplier. They are of the view that CAS packages that have many interfaces are difficult to use so far as speed is concerned. The Association of SMEs in could in collaboration with the Ghana Revenue Authority come out with a policy relating to the specifications that meets industry standards to the software industry for onwards design and development. The contributions of our research is not only to formalize knowledge related to our model on CAS selection criteria for SMEs but it can be applied in practice as a guide to both the SMEs and big reporting entities desiring to select an optimal CAS supplier for implementation among developed through to other developing countries as well. Academic institutions across the world could also collaborate with software developers and SME associations to develop curricula to train students in accountancy and information systems and technologies to enable smooth selection of computerised accounting vendors and implementation.

\section{Background Information}

\section{APPENDIX A}

1. What is your position in the company
a. Owner
b. Manager
c. Accountant
d. Cashier
e. Bookkeeper

2. How long have you been working with this company?
a. less than 1 year
b. 1-3 years
c. 4-6 years
d. 7-9 years
e. more than 10 years

3. Please provide an estimate of the number of employees in your company

4. Do You Keep Books of Accounts for Your Business?
a. Yes
b. No

5. How Do You Keep It?
a. Manual Method
b. Computerised Software Method
c. No Method

\section{CAS Implementation Experience}

6. If you have selected "b" in "question 4" have you ever had any experience in CAS implementation?
a. No
b. Yes, 
7. Did you have any CAS package in mind when you were going to the software market?
a. Yes
b. No

8. In the software market, were you overwhelmed with many CAS packages?
a. Yes
b. No

9. If you answered yes in question 8 above, which of the following personalities assisted you to select your CAS package? please tick one:
a. IT/Vendor support
b. Chartered Accountant
c. Advert
d. Advice from an similar SME manager

3 CAS Functionalities

10. Did you have in mind any feature/functionalities of CAS to aide you to select the best in the market?
a. Yes
b. No

11. If answered yes to question 10 above, which of the following basic features/functionalities did you consider before selecting CAS package? Please select as appropriate
a. Scalability
b. Capacity
c. Ease of data Input
d. Security
e. Speed of Installation
f. CAS Consultant
g. Reporting Capabilities
h. Error Handling
i. Data Validation
j. Audit Trail

12. If you selected "All" in question 11 did you encounter any challenges in your selected CAS Implementation and usage?
a. Yes
b. No

13. If you select "None" and "Some" in question 11 did you encounter difficulties in your CAS usage?
a. Yes
b. No

\section{CAS Training and Usage}

14. Were you given training during and after the CAS implementation process by the supplier?
a. Yes
b. No 


\section{If answered Yes to question 14, was the training related to how to use the CAS package to pass double entries using the necessary modules embedded in the application?}
a. Yes
b. No

\section{Reference}

Abu-Musa., Ahmad A., (2001), "Evaluating the Security of Computerized Accounting Information Systems: An Empirical Study on Egyptian Banking Industry" PhD Thesis, Aberdeen University, Scotland, UK.

Ahmad A. Abu-Musa (2005) "The Criteria For Selecting Accounting Software: A Theoretical Framework" Department of Accounting \& Management Information Systems King Fahd University of Petroleum \& Minerals Dhahran, Saudi Arabia

Accountancy (2013) "Computer and Computerised Accounting System" www.download.nos.org/srsec320newE/320EL12.pdf

Ayyagari, M., Beck, T. \& Demirguc-Kunt, A. (2007) Small and medium enterprises across the globe. Small Business Economics, [J], 29(4), pp.415-434

Bernard, H.R. (2012). Social research methods: Qualitative and quantitative approaches. Thousand Oaks, CA: Sage. Biswas, P. K., \& Baptista, A. (2012). Institutions and micro-enterprises demography: A study of selected EU countries, 1997-2006. Journal of Small Business and Entrepreneurship, 25(3), 283-306.

doi:10.1080/08276331.2012.10593574

Collins J. Carlton, (1999) “How to select the right accounting software”, Journal of Accountancy; New York; Vol. 188, Issue 2, PP. 61-69

Collins, J.C (2006). “Small Business Software Grows Up,” Journal of Accountancy, 201:3, , pp.50-56.

European Union, Commission Recommendation of (2003) concerning the definition of micro, small and mediumsized enterprises. Official Journal of the European Union, pp.36-41 2003 (J)

Fisher, Dorothy M.; Steven A. Fisher.,( 2001) "For rent: Are you considering an ASP for your accounting functions?", The National Public Accountant; Washington; Vol. 46, Issue 6, Aug, PP. 16-18.

Ghana Statistical Service (GSS) (2012), pp.31-40 “Population and Housing Census: Summary Report of Final Results

Heikkilä, T. S. \& Sääksjärvi, M. (1991) "Success of Software Packages in Small Businesses: An Exploratory Study,” European Journal of Information Systems, 1:3, pp.159-169.

Matzler. K., Sauerwein, E. and Heischmidt, K.A. (2003) "Importance-performance analysis revisited: the role of the factor structure of customer satisfaction", The Service Industries [J] Journal, , Vol. 23, No. 2, pp. 112 - 129

Michael. B., Dainese. F.,(2015)The Status of Computerized Accounting Software in Small American Businesses Miami University (Ohio)

Mpofu K, Watkins-Mathys L (2011) Understanding ICT adoption in the small firm sector in Southern Africa. J Syst Inf Technol 13(2):179-199

Randolph P. J.,"A Strategy for Finding the Right Accounting SoftwareA better understanding of your business operation"(2003)

http://www.journalofaccountancy.com/issues/2003/sep/astrategyforfindingtherightaccountingsoftware.html (accessed 11/08/2017)

Venkateswarlu P., (2010) “Implementing Accounting Software In Small Businesses In New Zealand: An Exploratory Investigation" [J] Accountancy Business and the Public Interest, pp.100. Vol. 9 